\title{
An unusual case of cyclopic and arhinia monster in Mehsana buffalo
}

Tarun V. Sutaria, Prajwalita T. Sutaria, Jayeshbhai S. Patel, Prakashkumar M. Chauhan

\author{
Teaching Veterinary Clinical Complex \\ College of Veterinary Science \& Animal Husbandry \\ Sardarkrushinagar Dantiwada Agricultural University, S.K.Nagar - 385506, Gujarat, India \\ Corresponding author: P M Chauhan, email: khanna_vet@yahoo.co.in \\ Received: 22-11-2011, Accepted: 31-12-2011, Publishē Online: 06-05-2012 \\ doi: $10.5455 /$ vetworld.2012.429-430
}

\begin{abstract}
To cite thisarticle:
Sutaria TV, Sutaria PT, Patel JS, Chauhan PM (2012) An unusual case of Cyclopic and Arhinia monster in Mehsana buffalo, Vet World, 5(7):429-430, doi: 10.5455/vetworld.2012.429-430
\end{abstract}

\section{I ntroduction}

Cyclopia is a rare form of holoprosencephaly and is a congenital disorder (birth defect) characterized by the failure of the embryonic prosencephalon to properly divide the orbits of the eye into two cavities. Although, most commonly seen in pig and sheep [1], it is also reported in goat [2] and cattle [3]. Similarly, congenital arhinia is an extremely rare anomaly consisting of an absence of external nasal structures and nasal passages. The present case study puts on a record of dystocia attributable to a unusual cyclopia with arhinia fetal monster calf having a typical monkey face and its successful per vaginum delivery through obstetrical maneuvers in Mehsana buffalo.

\section{Case history and clinical observations}

A four year old, apparently helathy primiparous, Mehsana buffalo at full term presented with a history of straining for the last seven hours and ruptured water bags. Gynaeco-clinical observation, revealed a dead fetus in anterior longitudinal presentation and left dorso-iliac position with both the forelimb flexed from shoulder, where as head was totally deviated downward so that only ear was palpated (Nap presentation).

\section{Treatment and Discussion}

The dystocial condition was corrected by obstetrical maneuvers and fetus was brought to normal presentation and posture. The delivery of dead female fetus was carried out by forced traction applied on both forelimbs and lower jaw after proper lubrication. Thereafter, buffalo was administered with Inj. Dextrose normal saline 5\% (2 Litre, I/V), Inj. Calcium borogluconate $(450 \mathrm{ml}, \mathrm{I} / \mathrm{V})$, Inj. Strpreptopenicillin (5gm, I/M), Inj. Meloxicam (20 ml, I/M) and Inj. Dexamethasone $(7.5 \mathrm{ml}, \mathrm{I} / \mathrm{M})$. Following above treatment, the placenta was expelled out at night without any assistance.

The morphological examination of removed dead female fetus revealed that the fetus having a single orbit with fused two eye balls (instead of one in typical cyclopia) with two separate corneas. Upper eyelid and eyelashes were present but both were absent in lower area of central eye. Absence of upper jaw leads to protrusion of tongue from base outside the mouth while lower jaw was long and normal (brachygnathism). Muzzle, nostrils and typical nose were absent (arhinia) and that area was covered with skin above the central eye. That means the nose and mouth fail to form, or the nose grows from the roof of the mouth obstructing airflow, resulting in suffocation which might lead to the death of fetus. Location of fused eyes in single orbit at forehead and absence of upper jaw and nose made the face of calf just like monkey face. The left ear was normal where as the right one was deformed and hairs were present all over the body. The skin over the forehead was open exposing a musculature mass and there was rudimentary visible fused eyes which also found in non-descript cow by Gupta and Anand [3]. Ozcan et $a l .$, [4] reported a atypical cyclopia in a brown swiss cross calf with most significant malformation such as the presence of a median orbita-like opening that did not contain an eyeball and other defects included prosencephalic aplasia, brachygnathia superior and arhinia. Similar type of arhinia and cyclopia in a German Fleckvieh calf were also reported by Schulze and Disti [5]. Khasatiya [6] also reported a cebocephalus (cyclopia) monster in a cross-bred cow and noted that epitheliogenesis imperfecta over the forehead and body, having rudimentary and separate eye balls and atypical deformed ears and jaw. Genetic 
problems [7] or toxins can cause problems in the embryonic forebrain-dividing process leads to development of such fetal monsters. One highly teratogenic alkaloid toxin that can cause cyclopia is cyclopamine or 2-deoxyjervine, found in the plant Veratrum californicum [8].

\section{References}

1. Roberts, S. J. (1971). Veterinary obstetrics and genital disease (Theriogenology), 2nd Edn. CBS Publisher and Distributors, New Delhi, pp. 6467.

2. Kantharaj, S. (2010). An unusual case of schistosomus reflexus with Cyclops in a goat a case repot. Ind. $J$. Ani. Reprod., 31(1): 93.

3. Gupta, K. A. and Anand, T. C. (2002). A cebocephalus (cyclopia) monster in a non descript cow. Ind. J. Ani. Reprod., 23(1): 8687.
4. Ozcan, K., Gürbulak, K., Takçi, I., Ozen, H., Kaçar, C. and Pancarci, M. S. (2006). Atypical cyclopia in a brown swiss cross calf: a case report. Anat. Histol, Embryol., 35(3):152-4.

5. Schulze, U. and Distl, O. (2006). Case report: arhinia and cyclopia in a German Fleckvieh calf. Dtsch Tierarztl Wochenschr. 113(6):236-9.

6. Khasatiya, C. T. (2010). A cebocephalus (cyclopia) monster in a cross - bred cow. Ind. J. Ani. Reprod., 31(1): 87.

7. Gilbert, S.F. (2000) Developmental Biology. Sinauer, Massachusettes.

8. Van kampen, K. R. and Ellis, L. C. (1972). Prolonged gestation in ewes ingesting veratrum californicum: morphological changes and steroid biosynthesis in the endocrine organs of cyclopic lambs, Journal of Endo., $52(3) ; 549560$. 